\section{Acesso dos usuários indígenas aos serviços de saúde de Cuiabá, Mato Grosso, Brasil}

\author{
Indigenous peoples' access to health services in \\ Cuiabá, Mato Grosso State, Brazil
}

Acceso de los usuarios indígenas a los servicios
de salud de Cuiabá, Mato Grosso, Brasil
Silvana Cardoso Gomes 1

Monique Azevedo Esperidião 2

doi: 10.1590/0102-311X00132215

\section{Resumo}

O presente estudo teve por objetivo avaliar o acesso dos usuários indígenas aos serviços de saúde de média e alta complexidades do Município de Cuiabá, Mato Grosso, Brasil, a partir da Casa de Saúde Indígena (CASAI) Cuiabá. Foi realizado um estudo de caso único na CASAI Cuiabá com abordagem qualitativa. Os dados foram obtidos por meio da observação das rotinas de trabalho da CASAI Cuiabá, entrevistas semiestruturadas com profissionais e gestores do Distrito Sanitário Especial Indígena (DSEI) Cuiabá e CASAI Cuiabá, e análise documental. Para análise dos dados, foi elaborada uma matriz derivada do modelo teórico-lógico de acessibilidade e validada por meio do método Delphi a um grupo de especialistas na temática de saúde indígena. Apesar de avanços trazidos pela CASAI na melhoria da acessibilidade indigena, persistem barreiras sócio-organizacionais, culturais e geográficas no acesso à média e alta complexidades do município estudado. Recomenda-se a formulação de estratégias específicas para a melhoria do acesso aos serviços de saúde dos povos indígenas mato-grossenses.

Saúde de Populações Indígenas; Acesso aos Serviços de Saúde; Avaliação em Saúde

\section{Correspondência}

S. C. Gomes

Rua Julio Domingos de Campos, Centro Político Administrativo, Cuiabá, MT 78049-902, Brasil.

s_cgomes@hotmail.com

1 Secretaria de Estado de Saúde de Mato Grosso, Cuiabá, Brasil. 2 Instituto de Saúde Coletiva, Universidade Federal da Bahia, Salvador, Brasil. 


\section{Introdução}

Diversas barreiras de acesso têm sido descritas como limitadoras da atenção à saúde dirigida aos povos indígenas em distintas regiões do mundo 1,2. Entre os principais obstáculos apontam-se barreiras organizacionais, geográficas e culturais, incluindo limitações relativas à ausência ou incipiência de intérpretes culturais que permitam maior comunicação das etnias com os serviços de saúde.

No México e na Guatemala foram identificadas barreiras geográficas (longas distâncias e elevado custo das passagens de transporte), organizacionais (limitações nos horários de funcionamento das unidades de saúde) e culturais (ausência de tradutores da língua indígena) como elementos limitadores do acesso dos povos indígenas aos serviços de saúde locais, além de discriminação e preconceito por parte dos profissionais de saúde no atendimento dessas populações 3,4 .

No Brasil, foi implementado no ano de 1999 o Subsistema de Atenção à Saúde Indígena, Sistema Único de Saúde (SASI/SUS), que está estruturado e organizado por meio dos Distritos Sanitários Especiais Indígenas (DSEIs), que são considerados ambientes étnicos e culturais dinâmicos e têm o dever de prestar atenção básica aos indígenas aldeados, sem guardar relação direta com os limites dos estados e municípios onde estão localizadas as terras indígenas 5. No ano de 2002, foi instituída a Política Nacional de Atenção à Saúde dos Povos Indígenas (PNASPI), propondo o respeito e reconhecimento da eficácia da medicina tradicional como um dos componentes na superação dos aspectos que tornam a população indígena vulnerável aos agravos 6 .

No entanto, ainda há poucos estudos que analisam ou versam de forma direta sobre o acesso da população indígena aos serviços de saúde. Estudos epidemiológicos realizados com diferentes povos indígenas do país concluíram que, dentre outros fatores, a dificuldade de acesso aos serviços de saúde, tanto da atenção básica nas aldeias quanto as ações e serviços especializados de média e alta complexidades ofertados pelos municípios e/ou estado, possibilita que essas minorias étnicas encontrem-se submetidas à maior risco de doenças 7,8,9,10.

Em Minas Gerais, um estudo realizado junto à etnia Xakriabá concluiu que a distância entre o posto de saúde e os domicílios dos indígenas é responsável pela redução do acesso e utilização dos serviços de saúde, devido à dispersão geográfica da população e às dificuldades de se obter transporte para o deslocamento dentro e fora das áreas indígenas 11. No Estado de Mato Grosso, estudos realizados junto ao povo Bororo no Município de Rondonópolis e ao povo Paresi em Tangará da Serra, constataram que os fluxos elaborados e formalizados por um plano distrital de saúde de um DSEI, para o acesso dos usuários aos serviços de saúde dos municípios de referência, não consideraram as articulações e pactuações realizadas pelos municípios na regional de saúde. Além disso, não se previram responsabilidades pela articulação do acesso à atenção básica fora da aldeia e aos níveis secundário e terciário 12,13 .

Tendo em vista contribuir para a identificação de barreiras socioculturais, sócio-organizacionais e geográficas enfrentadas pelos usuários no acesso aos serviços de saúde, o presente estudo buscou avaliar o acesso dos usuários indígenas aos serviços de média e alta complexidades do Município de Cuiabá, Mato Grosso.

\section{Metodologia}

Foi realizado um estudo de caso único sobre acesso dos usuários indígenas aos serviços de saúde de Cuiabá, com base em análise documental, observação in loco na Casa de Saúde Indígena (CASAI) de Cuiabá e entrevistas com informantes-chave. Para a avaliação do acesso, foi construído um modelo teórico-lógico da acessibilidade indígena aos serviços de média e alta complexidades, do qual derivou uma matriz de avaliação com as dimensões sócio-organizacional, sociocultural e geográfica. Foi constituído um comitê de seis especialistas em saúde indígena de diferentes estados do Brasil para a validação dos critérios contidos na matriz, utilizando-se como técnica o método Delphi. Os profissionais tinham como titulação mínima mestrado, sendo dois profissionais com doutorado, com média de experiência de trabalho em saúde indígena de 8,6 anos e de docência de 8,8 anos. Os especialistas haviam publicado em média quatro artigos na área de saúde indígena. 
Foram analisadas as atas das reuniões do Conselho Distrital de Saúde Indígena (CONDISI) DSEI Cuiabá (2007-2011), bem como realizada observação sistemática por dez dias na CASAI Cuiabá, onde buscou-se coletar dados sobre a estrutura física, além das rotinas de trabalho. As entrevistas, realizadas no ano de 2012, envolveram informantes-chave como técnicos e gestores da sede administrativa do DSEI Cuiabá e da CASAI Cuiabá.

\section{Local do estudo}

O Município de Cuiabá, capital do Estado de Mato Grosso, tem população estimada, segundo dados do Censo Demográfico de 2010 (Instituto Brasileiro de Geografia e Estatística. http://www.ibge.gov. br), em 551.098 habitantes.

O setor de saúde do município conta com unidades de assistências próprias e contratadas. A atenção especializada e hospitalar do município é constituída por um centro de reabilitação, cinco núcleos de reabilitação, três Centros de Atenção Psicossocial, nove residências terapêuticas, um laboratório municipal, um laboratório estadual, um laboratório contratado, seis policlínicas, um centro de especialidades médicas, um serviço ambulatorial especializado, 32 serviços de apoio, diagnóstico terapêutico, um hospital e pronto-socorro municipal, três hospitais filantrópicos, 18 hospitais contratados e um centro de controle de zoonozes 14 .

O DSEI Cuiabá, cuja sede administrativa fica na capital de Mato Grosso, é responsável pela organização dos serviços de saúde nos territórios indígenas de dez etnias: Nambikwara, Enawene-Nawe, Myky, Irantxe, Bakairi, Guató, Umutina, Paresi, Chiquitano e Bororo, distribuídos em oito polos-base e 110 aldeias cadastradas e reconhecidas oficialmente. A população indígena do DSEI Cuiabá conta com, aproximadamente, 6.939 pessoas, sendo que 11 Equipes Multidisciplinares de Saúde Indígena (EMSI) prestam atendimento nos territórios indígenas. Também compõem a estrutura administrativa do DSEI Cuiabá as CASAIs de Tangará da Serra, Rondonópolis e Cuiabá, que devem receber, alojar e alimentar os usuários indígenas e seus acompanhantes que necessitem de atendimento especializado ambulatorial e hospitalar nas cidades; prestar assistência de enfermagem 24 horas; marcar consultas e exames especializados; providenciar o acompanhamento e o retorno de pacientes e acompanhantes às aldeias de origem com as informações sobre o caso; e promover atividades de educação em saúde, produção artesanal e lazer para acompanhantes e pacientes em condições para tal exercício 6 .

Localizada na capital do estado onde se concentra uma parte dos serviços de média e a maioria dos procedimentos e serviços de alta complexidade, a CASAI Cuiabá, apesar de compor a estrutura administrativa do DSEI Cuiabá, serve de apoio para o atendimento da população indígena de todo o Estado de Mato Grosso.

\section{Modelo teórico-lógico de acesso}

Elaborou-se um modelo teórico-lógico de acesso previamente adaptado de uma pesquisa desenvolvida em um município da Bahia ${ }^{15}$. Esse modelo teve por base dimensões e critérios da relação de acessibilidade, e corresponde a uma imagem-objetivo de referência para a análise do acesso dos usuários indígenas do DSEI Cuiabá aos serviços de média e alta complexidades no município. Compreende-se por imagem-objetivo os princípios que orientam uma determinada política de saúde, podendo-se considerar que, de certa forma, apontam para a situação desejada ou ideal 16 (Figura 1).

Por acesso entende-se as características dos serviços de saúde que proporcionam ou dificultam a sua utilização por parte da população ${ }^{17}$. Foram estabelecidas três dimensões do acesso: sócio-organizacional, sociocultural e geográfica 17,18. Na dimensão sócio-organizacional são levantados os aspectos próprios da organização dos serviços de saúde, como horários de funcionamento das unidades e o tempo de espera para o atendimento, tanto da rede especializada quanto do serviço de saúde indígena. Na dimensão sociocultural estão descritos os aspectos culturais inerentes à população indígena que podem interferir na relação entre usuários e serviços de saúde. Na dimensão geográfica foram elencados aspectos relacionados à distribuição espacial dos recursos, localização das unidades de saúde, bem como a discussão sobre a existência de transporte específico e apropriado para os usuários indígenas. 


\section{Figure 1}

Modelo teórico-lógico de acesso dos usuários indígenas aos serviços de média e alta complexidades.

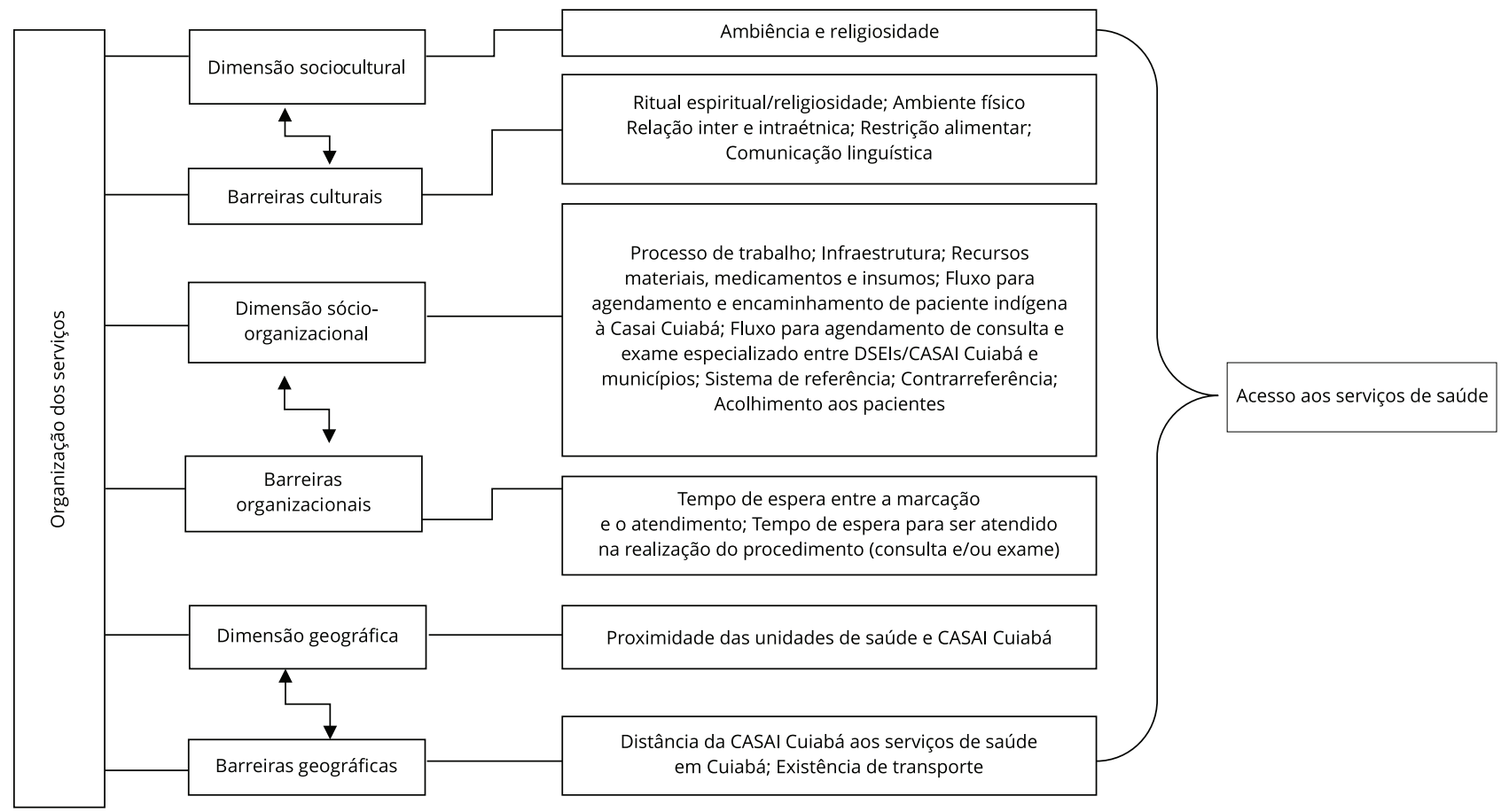

Fonte: adaptado de Cunha \& Vieira-da-Silva 15.

CASAI: Casa de Saúde Indígena; DSEls: Distritos Sanitários Especiais Indígenas.

De acordo com a imagem-objetivo proposta via modelo teórico-lógico, a organização dos serviços depende da correlação entre as dimensões estudadas, sendo que estas podem ou não garantir o pleno acesso aos serviços de saúde do Município de Cuiabá.

\section{Análise dos dados}

As informações coletadas foram validadas por meio de técnica de triangulação de dados, seja por meio da manutenção de perguntas-chave para os mesmos informantes para a comparação das respostas, seja pela contraposição dos dados informados com os dados coletados nos documentos analisados, a observação dos trabalhos realizados na CASAI Cuiabá e ainda pela bibliografia analisada e consultada sobre o tema 19 .

Para a construção das principais categorias de análise dos dados foi elaborada uma matriz de análise. Derivada do modelo teórico-lógico da acessibilidade, a matriz de análise foi submetida à validação de um grupo de seis de especialistas na temática de saúde indígena, e, após duas rodadas de análise, definiram as dimensões, subdimensões e critérios que foram utilizados neste estudo.

Para cada critério foi definida uma imagem-objetivo, com base na revisão da literatura e na análise dos especialistas participantes do método Delphi. As respostas e situações esperadas de cada critério foram classificadas como satisfatórias, parcialmente satisfatórias e insatisfatórias. A dimensão sócio-organizacional contou com a maior pontuação (100 pontos) por descrever um maior número de características referentes ao foco do estudo: média e alta complexidades do SUS. Já a pontuação máxima da dimensão sociocultural foi de 40 pontos, seguida da geográfica com 20 pontos. Os achados 
foram classificados por meio de comparação dos dados, em que foram atribuídos pontos ( 0 - insatisfatório, 5 - parcialmente satisfatório e 10 - satisfatório) a cada critério, sendo que para o resultado final foi realizada a somatória dos pontos atribuídos aos diferentes critérios, subdimensões e dimensões. A classificação final foi dividida em tercis, com os seguintes pontos de corte: satisfatório > 66\%; parcialmente satisfatório > 33\% e $\leq 66 \%$; e insatisfatório $\leq 33,3 \%$ (Tabela 1).

Todos os informantes foram esclarecidos quanto aos objetivos da pesquisa e assinaram o Termo de Consentimento Livre e Esclarecido, tendo sido assegurado o sigilo dos entrevistados. Este estudo foi aprovado pelo Comitê de Ética em Pesquisa do Instituto de Saúde Coletiva da Universidade Federal da Bahia (ISC/UFBA) conforme parecer no 151.56/2012, estando em concordância com a Resolução no 196/1996 do Conselho Nacional de Ética em Pesquisa (CONEP), que trata dos aspectos éticos de pesquisas que envolvem seres humanos.

\section{Resultados}

Os resultados sistematizados na matriz de análise foram agregados por dimensões, subdimensões e critérios que permitiram a classificação dos achados que serão apresentados a seguir com base nas dimensões sócio-organizacional, sociocultural e geográfica (Tabela 2).

A partir da análise geral de todas as dimensões, subdimensões e seus respectivos critérios, o percentual alcançado (41\%) permite categorizar como parcialmente satisfatórias as características dos serviços da saúde indígena e dos serviços especializados de Cuiabá no acesso dos usuários indígenas aos serviços de saúde de média e alta complexidades de Cuiabá.

\section{Dimensão sócio-organizacional}

Esta dimensão foi classificada como parcialmente satisfatória (45\%). O critério regulação dos pacientes indígenas aos serviços de média e alta complexidades a partir dos municípios de origem das aldeias foi classificado como parcialmente satisfatório, pois foi identificado que tal barreira acontece com a minoria dos pacientes indígenas encaminhados a Cuiabá.

Há existência de fluxos institucionais entre os diferentes DSEIs para o encaminhamento dos pacientes à CASAI Cuiabá, no entanto, não foi identificado que os fluxos tenham sido normatizados entre os mesmos. Para o encaminhamento dos pacientes foram identificadas diferentes formas de comunicação: $e$-mail, telefones e rádio, embora a CASAI Cuiabá tenha informado aos demais distritos sanitários com população indígena em Mato Grosso de que tal ato seja pela via de e-mail ou ofício. A informalidade no encaminhamento foi apontada como fator impeditivo para o acesso aos serviços em Cuiabá:

"...Ligam em cima da hora e para se desculpar dizem: 'tá indo com passagem de volta'. Geralmente quando a CASAI tá muito lotada e é realidade, e eu não tenho onde colocar eu falo: não manda porque eu não tenho onde colocar. E aí não manda e perde a consulta, perde a vaga e a oportunidade de consultar" (Profissional 02).

Percebe-se fragilidade no processo de articulação entre o DSEI Cuiabá e os municípios da área de abrangência do distrito para estabelecimento de fluxos. As relações nesse campo são construídas conforme a sensibilidade do gestor municipal à causa indígena, e com base nas relações de amizade entre os profissionais da saúde indígena e os profissionais de saúde dos municípios. Também foram detectadas dificuldades na relação entre os gestores por falta de clareza entre os pares sobre os papéis a serem desempenhados pelos diferentes entes federados na saúde indígena.

A contrarreferência dos pacientes indígenas, com raras exceções e a pedido dos profissionais dos DSEIs, é realizada pelos profissionais dos serviços de saúde de Cuiabá. Porém, todos os pacientes que ficam alojados na CASAI Cuiabá retornam aos seus municípios de origem com contrarreferência preenchida em formulário específico pelos profissionais da instituição, uma vez que tal tarefa faz parte das atribuições do serviço.

Evidenciou-se também um fator muito agravante: a ausência de informações de referência dos pacientes que são encaminhados para Cuiabá, seja do município de origem, da equipe de saúde indígena local ou da equipe de outra CASAI em que o paciente esteve alojado: 
Tabela 1

Matriz de dimensões, critérios e gradações para análise das ações de acesso a serviços de saúde de média e alta complexidades do Município de Cuiabá, Mato Grosso, Brasil.

\begin{tabular}{|c|c|c|c|c|c|c|}
\hline \multirow[t]{2}{*}{ Dimensão } & \multirow[t]{2}{*}{ Subdimensão } & \multirow[t]{2}{*}{ Critérios } & \multicolumn{4}{|c|}{ Gradações } \\
\hline & & & Satisfatório & $\begin{array}{c}\text { Parcialmente } \\
\text { Satisfatório }\end{array}$ & Insatisfatório & $\begin{array}{c}\text { Pontuação } \\
\text { máxima }\end{array}$ \\
\hline \multirow[t]{3}{*}{$\begin{array}{l}\text { Sócio- } \\
\text { organizacional }\end{array}$} & $\begin{array}{c}\text { Sistema de } \\
\text { referência e } \\
\text { contrarreferência }\end{array}$ & $\begin{array}{c}\text { Regulação dos } \\
\text { pacientes indígenas } \\
\text { aos serviços de } \\
\text { média e alta } \\
\text { complexidades } \\
\text { de Cuiabá pelos } \\
\text { municípios de } \\
\text { origem da aldeia }\end{array}$ & $\begin{array}{l}\text { Os pacientes } \\
\text { indígenas são } \\
\text { regulados aos } \\
\text { serviços de saúde } \\
\text { de média e alta } \\
\text { complexidades } \\
\text { de Cuiabá pelos } \\
\text { municípios de } \\
\text { origem da aldeia } \\
\text { (10 pontos) }\end{array}$ & $\begin{array}{c}\text { A maioria }(50 \%+ \\
\text { 1) dos pacientes } \\
\text { indígenas é regulada } \\
\text { para os serviços de } \\
\text { saúde de média e } \\
\text { alta complexidades } \\
\text { de Cuiabá pelos } \\
\text { municípios de } \\
\text { origem das aldeias, } \\
\text { mas ainda há } \\
\text { casos de pacientes } \\
\text { encaminhados à } \\
\text { CASAI Cuiabá sem a } \\
\text { devida regulação (5 } \\
\text { pontos) }\end{array}$ & $\begin{array}{l}\text { Os pacientes } \\
\text { indígenas não são } \\
\text { regulados para os } \\
\text { serviços de saúde } \\
\text { de média e alta } \\
\text { complexidades } \\
\text { de Cuiabá pelos } \\
\text { municípios de } \\
\text { origem das aldeias e } \\
\text { são encaminhados } \\
\text { para a CASAl Cuiabá } \\
\text { (0 ponto) }\end{array}$ & 10 \\
\hline & & $\begin{array}{c}\text { Existência de } \\
\text { fluxo estabelecido } \\
\text { institucionalmente } \\
\text { entre os DSEls para } \\
\text { encaminhamento } \\
\text { de usuários à CASAI } \\
\text { Cuiabá }\end{array}$ & $\begin{array}{c}\text { Há fluxo } \\
\text { estabelecido } \\
\text { institucionalmente } \\
\text { entre os } \\
\text { DSEls para } \\
\text { encaminhamento } \\
\text { de pacientes à } \\
\text { CASAI Cuiabá (10 } \\
\text { pontos) }\end{array}$ & $\begin{array}{c}\text { Há fluxo } \\
\text { estabelecido, porém } \\
\text { não normatizado e/ } \\
\text { ou não respeitado } \\
\text { entre os DSEls para } \\
\text { o encaminhamento } \\
\text { de pacientes à CASAI } \\
\text { Cuiabá (5 pontos) }\end{array}$ & $\begin{array}{c}\text { Não há fluxo } \\
\text { estabelecido } \\
\text { institucionalmente } \\
\text { entre os DSEls para } \\
\text { encaminhamento de } \\
\text { pacientes à CASAI } \\
\text { Cuiabá (0 ponto) }\end{array}$ & 10 \\
\hline & & $\begin{array}{c}\text { Existência de } \\
\text { fluxo estabelecido } \\
\text { institucionalmente } \\
\text { pelo DSEl Cuiabá } \\
\text { em articulação } \\
\text { com os municípios } \\
\text { de sua área de } \\
\text { abrangência }\end{array}$ & $\begin{array}{c}\text { Há fluxo } \\
\text { estabelecido } \\
\text { institucionalmente } \\
\text { entre o DSEI } \\
\text { Cuiabá e todos } \\
\text { os municípios } \\
\text { de sua área de } \\
\text { abrangência } \\
\text { para acesso dos } \\
\text { usuários indígenas } \\
\text { aos diferentes } \\
\text { níveis de atenção } \\
\text { do SuS (10 pontos) }\end{array}$ & $\begin{array}{c}\text { Há fluxo } \\
\text { estabelecido } \\
\text { institucionalmente } \\
\text { entre o DSEI Cuiabá } \\
\text { e alguns municípios } \\
\text { de sua área de } \\
\text { abrangência para } \\
\text { acesso dos usuários } \\
\text { indígenas aos } \\
\text { diferentes níveis de } \\
\text { atenção do SUS (5 } \\
\text { pontos) }\end{array}$ & $\begin{array}{c}\text { Não há fluxo } \\
\text { estabelecido } \\
\text { institucionalmente } \\
\text { entre o DSEl Cuiabá } \\
\text { e os municípios } \\
\text { de sua área de } \\
\text { abrangência para } \\
\text { acesso dos usuários } \\
\text { indígenas aos } \\
\text { diferentes níveis de } \\
\text { atenção do SUS (0 } \\
\text { pontos) }\end{array}$ & 10 \\
\hline
\end{tabular}

(continua) 


\begin{tabular}{|c|c|c|c|c|c|c|}
\hline \multirow[t]{2}{*}{ Dimensão } & \multirow[t]{2}{*}{ Subdimensão } & \multirow[t]{2}{*}{ Critérios } & \multicolumn{4}{|c|}{ Gradações } \\
\hline & & & Satisfatório & $\begin{array}{l}\text { Parcialmente } \\
\text { Satisfatório }\end{array}$ & Insatisfatório & $\begin{array}{l}\text { Pontuação } \\
\text { máxima }\end{array}$ \\
\hline & \multirow{3}{*}{$\begin{array}{c}\text { Serviço de } \\
\text { apoio ao } \\
\text { usuário } \\
\text { indígena: } \\
\text { CASAI Cuiabá }\end{array}$} & $\begin{array}{l}\text { Retorno dos } \\
\text { pacientes } \\
\text { indígenas com a } \\
\text { con- trarreferência } \\
\text { preenchida em } \\
\text { formulário específico } \\
\text { pelos profissionais } \\
\text { dos serviços de } \\
\text { saúde de Cuiabá }\end{array}$ & $\begin{array}{l}\text { Os pacientes } \\
\text { indígenas recebem } \\
\text { contrarreferência } \\
\text { preenchida em } \\
\text { formulário específico } \\
\text { pelos profissionais } \\
\text { dos serviços de } \\
\text { saúde (1 serviço ou } \\
\text { mais) de Cuiabá (10 } \\
\text { pontos) }\end{array}$ & $\begin{array}{l}\text { A contrarreferência } \\
\text { dos pacientes } \\
\text { indígenas é realizada } \\
\text { somente pela } \\
\text { CASAI Cuiabá em } \\
\text { formulário específico } \\
\text { do estabelecimento } \\
\text { (5 pontos) }\end{array}$ & $\begin{array}{c}\text { Não é realizada } \\
\text { nenhuma } \\
\text { contrarreferência, } \\
\text { tanto pelos serviços } \\
\text { de saúde de Cuiabá } \\
\text { quanto pela CASAI } \\
\text { Cuiabá, para os } \\
\text { pacientes indígenas } \\
\text { que foram atendidos } \\
\text { nos serviços de } \\
\text { saúde de Cuiabá (0 } \\
\text { ponto) }\end{array}$ & 10 \\
\hline & & $\begin{array}{l}\text { Adequação } \\
\text { arquitetônica da } \\
\text { CASAl para o uso de } \\
\text { redes e/ou esteiras } \\
\text { para pacientes } \\
\text { indígenas que } \\
\text { não queiram ficar } \\
\text { instalados em camas }\end{array}$ & $\begin{array}{c}\text { A CASAI Cuiabá } \\
\text { conta comi } \\
\text { instalações } \\
\text { adequadas } \\
\text { arquitetonicamente } \\
\text { para o uso de rede e } \\
\text { esteiras (10 pontos) }\end{array}$ & $\begin{array}{l}\text { A CASAI Cuiabá } \\
\text { tem adequação } \\
\text { arquitetônica, porém } \\
\text { as instalações } \\
\text { físicas não estão } \\
\text { adequadas (ausência } \\
\text { ou número } \\
\text { insuficiente de } \\
\text { redes, esteiras, } \\
\text { lençóis e colchões) } \\
\text { para a hospedagem } \\
\text { de pacientes } \\
\text { indígenas (5 pontos) }\end{array}$ & $\begin{array}{l}\text { A CASAI Cuiabá não } \\
\text { tem instalações } \\
\text { adequadas } \\
\text { arquitetonicamente } \\
\text { para o uso de rede e } \\
\text { esteiras (0 pontos) }\end{array}$ & 10 \\
\hline & & $\begin{array}{c}\text { Presença de } \\
\text { acompanhantes } \\
\text { que falam a língua } \\
\text { indígena para os } \\
\text { usuários indígenas } \\
\text { que não falam a } \\
\text { língua portuguesa } \\
\text { na CASAl e no } \\
\text { acompanhamento } \\
\text { aos serviços de } \\
\text { saúde }\end{array}$ & $\begin{array}{c}\text { É garantida a } \\
\text { presença de } \\
\text { acompanhantes } \\
\text { que falam a língua } \\
\text { indígena para os } \\
\text { usuários indígenas } \\
\text { que não falam a } \\
\text { língua portuguesa } \\
\text { em sua hospedagem } \\
\text { na CASAl Cuiabá e } \\
\text { em todas as etapas } \\
\text { de seu tratamento } \\
\text { nos serviços } \\
\text { especializados de } \\
\text { saúde (10 pontos) }\end{array}$ & $\begin{array}{l}\text { É garantida a } \\
\text { presença de } \\
\text { acompanhantes } \\
\text { que falam a língua } \\
\text { indígena para os } \\
\text { usuários indígenas } \\
\text { que não falam a } \\
\text { língua portuguesa } \\
\text { somente em } \\
\text { algumas etapas de } \\
\text { sua permanência no } \\
\text { Município de Cuiabá } \\
\text { (5 pontos) }\end{array}$ & $\begin{array}{l}\text { Não é garantida } \\
\text { a presença de } \\
\text { acompanhantes } \\
\text { que falam a língua } \\
\text { indígena para os } \\
\text { usuários indígenas } \\
\text { que não falam a } \\
\text { língua portuguesa } \\
\text { nas etapas de sua } \\
\text { hospedagem na } \\
\text { CASAI Cuiabá e de } \\
\text { seu tratamento } \\
\text { nos serviços } \\
\text { especializados de } \\
\text { saúde (0 ponto) }\end{array}$ & 10 \\
\hline
\end{tabular}

(continua) 
Tabela 1 (continuação)

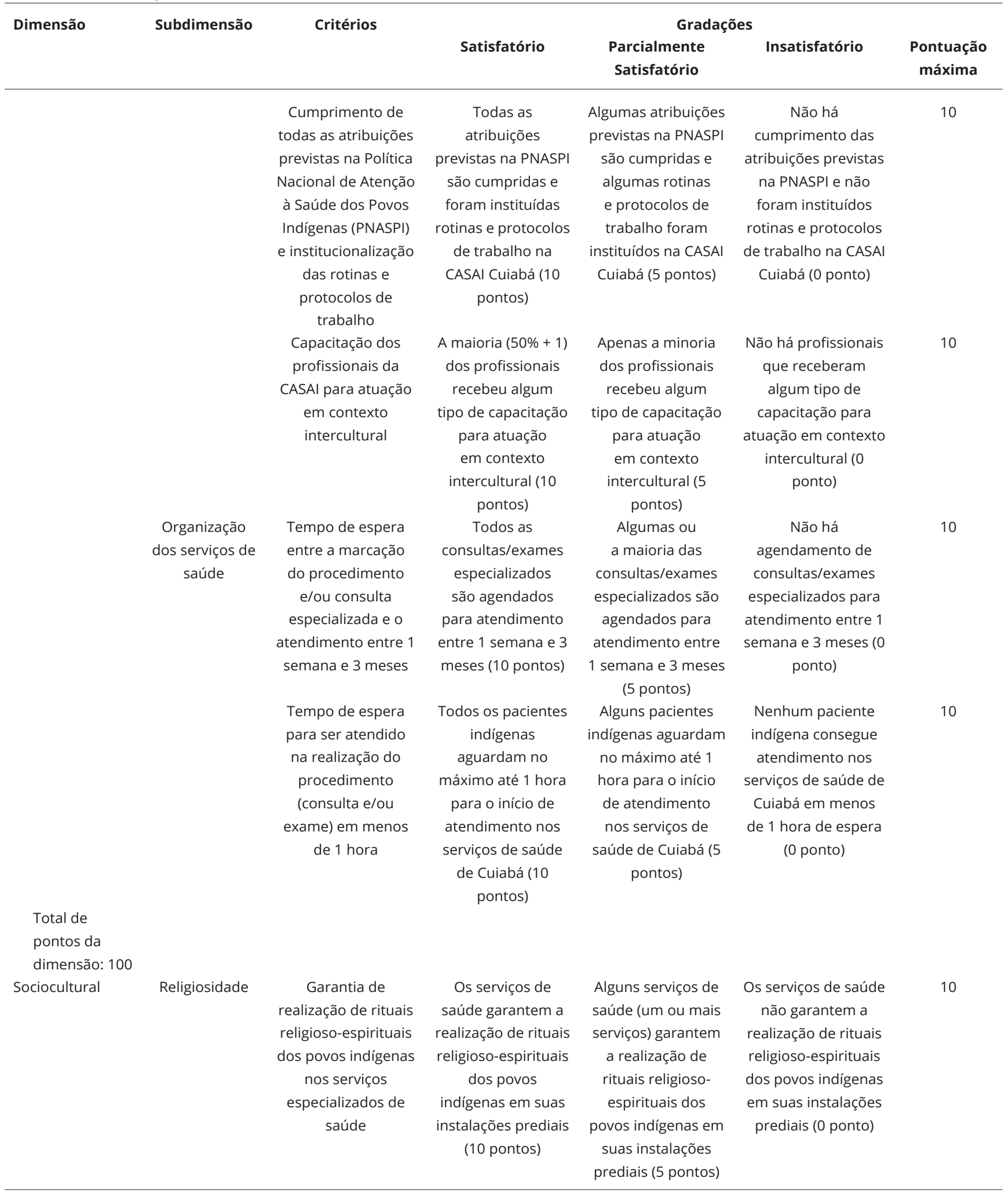

(continua) 
Tabela 1 (continuação)

\begin{tabular}{|c|c|c|c|c|c|c|}
\hline \multirow[t]{2}{*}{ Dimensão } & \multirow[t]{2}{*}{ Subdimensão } & \multirow[t]{2}{*}{ Critérios } & \multicolumn{4}{|c|}{ Gradações } \\
\hline & & & Satisfatório & $\begin{array}{l}\text { Parcialmente } \\
\text { Satisfatório }\end{array}$ & Insatisfatório & $\begin{array}{c}\text { Pontuação } \\
\text { máxima }\end{array}$ \\
\hline & Ambiência & $\begin{array}{c}\text { Adequação } \\
\text { arquitetônica dos } \\
\text { serviços de saúde } \\
\text { especializados } \\
\text { para o uso } \\
\text { de redes por } \\
\text { pacientes } \\
\text { indígenas que } \\
\text { não queiram } \\
\text { ficar instalados } \\
\text { em camas } \\
\text { hospitalares }\end{array}$ & $\begin{array}{l}\text { Os serviços de saúde } \\
\text { estão adequados } \\
\text { arquitetonicamente } \\
\text { para o uso de } \\
\text { redes por pacientes } \\
\text { indígenas que } \\
\text { não queiram ficar } \\
\text { instalados em camas } \\
\text { hospitalares (10 } \\
\text { pontos) }\end{array}$ & $\begin{array}{l}\text { Alguns serviços de } \\
\text { saúde (um ou mais) } \\
\text { estão adequados } \\
\text { arquitetonicamente } \\
\text { para o uso de } \\
\text { redes por pacientes } \\
\text { indígenas que } \\
\text { não queiram ficar } \\
\text { instalados em camas } \\
\text { hospitalares (5 } \\
\text { pontos) }\end{array}$ & $\begin{array}{l}\text { Não há serviços de } \\
\text { saúde adequados } \\
\text { arquitetonicamente } \\
\text { para o uso de } \\
\text { redes por pacientes } \\
\text { indígenas que } \\
\text { não queiram ficar } \\
\text { instalados em camas } \\
\text { hospitalares (0 } \\
\text { ponto) }\end{array}$ & 10 \\
\hline & $\begin{array}{l}\text { Relações inter } \\
\text { e intraétnicas }\end{array}$ & $\begin{array}{l}\text { Capacitação dos } \\
\text { profissionais dos } \\
\text { serviços de saúde } \\
\text { especializados } \\
\text { para atuação } \\
\text { em contexto } \\
\text { intercultural }\end{array}$ & $\begin{array}{l}\text { Os profissionais dos } \\
\text { serviços de saúde } \\
\text { especializados } \\
\text { possuem } \\
\text { capacitação } \\
\text { e habilidade } \\
\text { (sensibilidade e } \\
\text { empatia cultural) } \\
\text { para atuação } \\
\text { em contexto } \\
\text { intercultural (10 } \\
\text { pontos) }\end{array}$ & $\begin{array}{l}\text { Alguns profissionais } \\
\text { dos serviços de } \\
\text { saúde especializados } \\
\text { possuem } \\
\text { capacitação } \\
\text { e habilidade } \\
\text { (sensibilidade e } \\
\text { empatia cultural) } \\
\text { para atuação } \\
\text { em contexto } \\
\text { intercultural (5 } \\
\text { pontos) }\end{array}$ & $\begin{array}{l}\text { Não há profissionais } \\
\text { dos serviços de } \\
\text { saúde especializados } \\
\text { que possuam } \\
\text { capacitação } \\
\text { e habilidade } \\
\text { (sensibilidade e } \\
\text { empatia cultural) } \\
\text { para atuação } \\
\text { em contexto } \\
\text { intercultural (0 } \\
\text { ponto) }\end{array}$ & 10 \\
\hline & Alimentação & $\begin{array}{c}\text { Alimentação } \\
\text { adequada } \\
\text { aos hábitos } \\
\text { alimentares e } \\
\text { dieta dos usuários } \\
\text { indígenas }\end{array}$ & $\begin{array}{c}\text { Há fornecimento } \\
\text { de alimentação } \\
\text { adequada aos } \\
\text { hábitos alimentares } \\
\text { e dieta dos usuários } \\
\text { indígenas na CASAI } \\
\text { Cuiabá e nos } \\
\text { serviços de saúde } \\
\text { especializados (10 } \\
\text { pontos) }\end{array}$ & $\begin{array}{l}\text { Há fornecimento } \\
\text { de alimentação } \\
\text { adequada aos } \\
\text { hábitos alimentares } \\
\text { e dieta dos usuários } \\
\text { indígenas na CASAI } \\
\text { Cuiabá, porém não } \\
\text { há garantia nos } \\
\text { serviços de saúde } \\
\text { especializados ou } \\
\text { vice-versa (5 pontos) }\end{array}$ & $\begin{array}{c}\text { Não há } \\
\text { fornecimento } \\
\text { de alimentação } \\
\text { adequada aos } \\
\text { hábitos alimentares } \\
\text { e dieta dos usuários } \\
\text { indígenas na CASAI } \\
\text { Cuiabá e nem nos } \\
\text { serviços de saúde } \\
\text { especializados (0 } \\
\text { ponto) }\end{array}$ & 10 \\
\hline $\begin{array}{l}\text { Total de } \\
\text { pontos da } \\
\text { dimensão: } 40\end{array}$ & & & & & & \\
\hline
\end{tabular}

(continua) 
Tabela 1 (continuação)

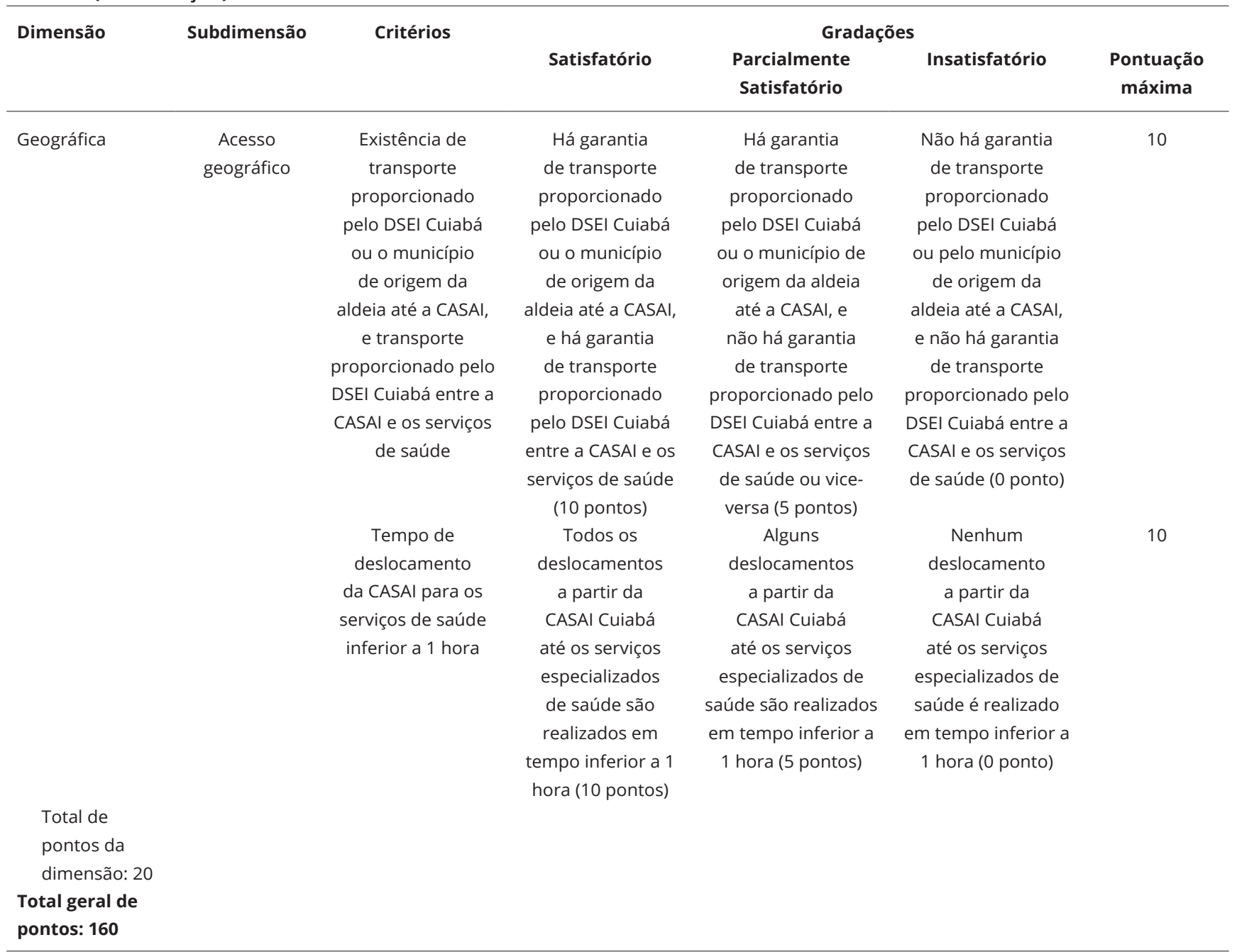

CASAI: Casa de Saúde Indígena; DSEls: Distritos Sanitários Especiais Indígenas; PNASPI: Política Nacional de Atenção à Saúde dos Povos Indígenas; SUS: Sistema Único de Saúde. 


\section{Tabela 2}

Matriz de dimensões e critérios para análise das ações de acesso a serviços de saúde de média e alta complexidades do Município de Cuiabá, Mato Grosso, Brasil, pontuação obtida, classificação final por critério, dimensão e resultado final.

\begin{tabular}{|c|c|c|c|c|c|c|}
\hline \multirow[t]{2}{*}{ Dimensão } & \multirow[t]{2}{*}{ Subdimensão } & \multirow[t]{2}{*}{ Critérios } & \multicolumn{2}{|c|}{ Pontuação } & \multirow[t]{2}{*}{ Fonte de evidência } & \multirow[t]{2}{*}{ Classificação final } \\
\hline & & & Pontos & $\%$ & & \\
\hline \multirow{29}{*}{$\begin{array}{l}\text { Socio- } \\
\text { organizacional }\end{array}$} & Sistema de & Regulação dos pacientes & 5 & 50 & Entrevistas e & Parcialmente satisfatório \\
\hline & $\begin{array}{c}\text { referencia e } \\
\text { contrarreferência }\end{array}$ & $\begin{array}{l}\text { indigenas aos serviços de } \\
\text { média e alta complexidades }\end{array}$ & & & documentos & \\
\hline & & de Cuiabá pelos municípios & & & & \\
\hline & & de origem da aldeia & & & & \\
\hline & & Existência de & & & Entrevistas e & Parcialmente satisfatório \\
\hline & & fluxo estabelecido & & & documentos & \\
\hline & & institucionalmente & 5 & 50 & & \\
\hline & & entre os DSEls para & & & & \\
\hline & & encaminhamento de & & & & \\
\hline & & usuários à Casai Cuiabá & & & & \\
\hline & & Existência de & 5 & 50 & Entrevistas e & Parcialmente satisfatório \\
\hline & & fluxo estabelecido & & & documentos & \\
\hline & & institucionalmente pelo & & & & \\
\hline & & DSEI Cuiabá em articulação & & & & \\
\hline & & com os municípios de sua & & & & \\
\hline & & área de abrangência & & & & \\
\hline & & Retorno dos pacientes & 5 & 50 & Entrevistas & Parcialmente satisfatório \\
\hline & & indígenas com a & & & & \\
\hline & & transferência preenchida & & & & \\
\hline & & em formulário específico & & & & \\
\hline & & pelos profissionais dos & & & & \\
\hline & & serviços de saúde de & & & & \\
\hline & & Cuiabá & & & & \\
\hline & Serviço de apoio & Adequação arquitetônica & 5 & 50 & Entrevistas, documentos e & Parcialmente satisfatório \\
\hline & ao usuário & da CASAI para o uso & & & observação & \\
\hline & indígena: CASAI & de redes e/ou esteiras & & & & \\
\hline & Cuiabá & por pacientes indígenas & & & & \\
\hline & & que não queiram ficar & & & & \\
\hline & & instalados em camas & & & & \\
\hline
\end{tabular}

(continua)

acompanhantes-familiares oriundos da aldeia poderão acompanhá-los aos serviços de saúde de Cuiabá, devido aos problemas de transporte e locomoção da unidade (CASAI).

A CASAI Cuiabá garante e cumpre os serviços básicos referentes à rotina, protocolos e cumprimento das atribuições de uma CASAI. Porém, não ficou evidenciada a promoção regular e institucional de atividades de educação em saúde e de produção artesanal ou lazer para os acompanhantes, e mesmo para os pacientes em condições para o exercício destas atividades. Porém, foi presenciada e relatada atividade que trata da constituição de grupos de estudos dos profissionais da CASAI Cuiabá em cujos encontros, no período do expediente, são debatidas temáticas referentes às relações humanas e interpessoais.

Os profissionais de saúde, em geral, informaram desconhecer algum tipo de protocolo de trabalho ou norma instituída de maneira formal para o desenvolvimento de suas atividades na CASAI Cuiabá. Eles relataram que suas atribuições e rotinas de serviço foram constituídas com base em atividades que já vinham sendo desenvolvidas em anos anteriores por outros profissionais ou por meio de suas atribuições técnicas profissionais já garantidas em legislações próprias. 
Tabela 2 (continuação)

\begin{tabular}{|c|c|c|c|c|c|c|}
\hline \multirow[t]{2}{*}{ Dimensão } & \multirow[t]{2}{*}{ Subdimensão } & \multirow[t]{2}{*}{ Critérios } & \multicolumn{2}{|c|}{ Pontuação } & \multirow[t]{2}{*}{ Fonte de evidência } & \multirow[t]{2}{*}{ Classificação final } \\
\hline & & & Pontos & $\%$ & & \\
\hline & & $\begin{array}{c}\text { Presença de } \\
\text { acompanhantes } \\
\text { que falam a língua } \\
\text { indígena para os } \\
\text { usuários indígenas } \\
\text { que não falam a } \\
\text { língua portuguesa } \\
\text { na CASAl e no } \\
\text { acompanhamento } \\
\text { aos serviços de } \\
\text { saúde }\end{array}$ & 5 & 50 & Entrevistas e observação & Parcialmente satisfatório \\
\hline & & $\begin{array}{l}\text { Cumprimento de } \\
\text { todas as atribuições } \\
\text { previstas na } \\
\text { PNASPI e } \\
\text { institucionalização } \\
\text { das rotinas e } \\
\text { protocolos de } \\
\text { trabalho }\end{array}$ & 5 & 50 & Entrevistas e observação & Parcialmente satisfatório \\
\hline & & $\begin{array}{l}\text { Capacitação dos } \\
\text { profissionais da } \\
\text { CASAI para atuação } \\
\text { em contexto } \\
\text { intercultural }\end{array}$ & 5 & 50 & Entrevistas e documentos & Parcialmente satisfatório \\
\hline & $\begin{array}{l}\text { Organização dos } \\
\text { serviços de saúde }\end{array}$ & $\begin{array}{c}\text { Tempo de espera } \\
\text { entre a marcação } \\
\text { do procedimento } \\
\text { e/ou consulta } \\
\text { especializada e } \\
\text { o atendimento } \\
\text { entre } 1 \text { semana e } 3 \\
\text { meses }\end{array}$ & 5 & 50 & Entrevistas & Parcialmente satisfatório \\
\hline & & $\begin{array}{l}\text { Tempo de espera } \\
\text { para ser atendido } \\
\text { na realização do } \\
\text { procedimento } \\
\text { (consulta e/ou } \\
\text { exame) em menos } \\
\text { de } 1 \text { hora }\end{array}$ & 0 & 0 & Entrevistas & Insatisfatório \\
\hline $\begin{array}{l}\text { Total da } \\
\text { dimensão }\end{array}$ & & & 45 & 45 & - & Parcialmente satisfatória \\
\hline
\end{tabular}

(continua)

No que diz respeito à capacitação dos profissionais da CASAI Cuiabá para atuação em contexto intercultural, o item analisado foi classificado como parcialmente satisfatório. Foi relatado que a maioria dos profissionais que atua no estabelecimento recebeu algum tipo de capacitação na área de antropologia, com vistas a uma atuação intercultural. No entanto, no levantamento documental constatou-se que em diferentes anos, tanto os profissionais de saúde não indígenas quanto os conselheiros indígenas, discutiram reiteradamente a necessidade de capacitação dos profissionais de saúde das CASAIs para a atuação intercultural. 
Tabela 2 (continuação)

\begin{tabular}{|c|c|c|c|c|c|c|}
\hline \multirow[t]{2}{*}{ Dimensão } & \multirow[t]{2}{*}{ Subdimensão } & \multirow[t]{2}{*}{ Critérios } & \multicolumn{2}{|c|}{ Pontuação } & \multirow[t]{2}{*}{ Fonte de evidência } & \multirow[t]{2}{*}{ Classificação final } \\
\hline & & & Pontos & $\%$ & & \\
\hline \multirow[t]{4}{*}{ Sociocultural } & Religiosidade & $\begin{array}{l}\text { Garantia de } \\
\text { realização de } \\
\text { rituais religioso- } \\
\text { espirituais dos } \\
\text { povos indígenas } \\
\text { nos serviços } \\
\text { especializados de } \\
\text { saúde }\end{array}$ & 10 & 100 & Entrevistas & Satisfatório \\
\hline & Ambiência & $\begin{array}{c}\text { Adequação } \\
\text { arquitetônica dos } \\
\text { serviços de saúde } \\
\text { especializados para } \\
\text { o uso de redes por } \\
\text { pacientes indígenas } \\
\text { que não queiram } \\
\text { ficar instalados em } \\
\text { camas hospitalares }\end{array}$ & 0 & 0 & Entrevistas & Insatisfatório \\
\hline & $\begin{array}{l}\text { Relações inter e } \\
\text { intraétnicas }\end{array}$ & $\begin{array}{l}\text { Capacitação dos } \\
\text { profissionais dos } \\
\text { serviços de saúde } \\
\text { especializados } \\
\text { para atuação } \\
\text { em contexto } \\
\text { intercultural }\end{array}$ & 0 & 0 & Entrevistas e documentos & Insatisfatório \\
\hline & Alimentação & $\begin{array}{c}\text { Alimentação } \\
\text { adequada aos } \\
\text { hábitos alimentares } \\
\text { e dieta dos usuários } \\
\text { indígenas }\end{array}$ & 5 & 50 & Entrevistas & Parcialmente satisfatório \\
\hline $\begin{array}{l}\text { Total da } \\
\text { dimensão }\end{array}$ & & & 15 & 37,5 & - & Parcialmente satisfatório \\
\hline \multirow[t]{2}{*}{ Geográfica } & $\begin{array}{c}\text { Acesso } \\
\text { geográfico }\end{array}$ & $\begin{array}{l}\text { Existência de } \\
\text { transporte } \\
\text { proporcionado } \\
\text { pelo DSEI Cuiabá } \\
\text { ou o município } \\
\text { de origem da } \\
\text { aldeia até a CASAl, } \\
\text { e transporte } \\
\text { proporcionado pelo } \\
\text { DSEI Cuiabá entre a } \\
\text { CASAl e os serviços } \\
\text { de saúde }\end{array}$ & 5 & 50 & Entrevistas e documentos & Parcialmente satisfatório \\
\hline & & $\begin{array}{c}\text { Tempo de } \\
\text { deslocamento } \\
\text { da Casai para os } \\
\text { serviços de saúde } \\
\text { inferior a } 1 \text { hora }\end{array}$ & 0 & 0 & Entrevistas, documentos e observação & Insatisfatório \\
\hline $\begin{array}{l}\text { Total da } \\
\text { dimensão }\end{array}$ & & & 5 & 25 & - & Insatisfatório \\
\hline Total geral & & & 65 & 41 & & Parcialmente satisfatório \\
\hline
\end{tabular}

CASAI: Casa de Saúde Indígena; DSEls: Distritos Sanitários Especiais Indígenas; PNASPI: Política Nacional de Atenção à Saúde dos Povos Indígenas. 
O critério relativo ao tempo médio que o usuário indígena aguarda no município de origem ou na própria aldeia para agendamento de consulta e/ou exame especializado foi considerado parcialmente satisfatório. Foi verificado que, de uma forma geral, o tempo aguardado é menor do que três meses, sendo que em algumas especialidades (reumatologia, dermatologia, neurologia e oncologia) e exames (ecocardiograma), este tempo é indefinido, bem acima dos três meses.

Já o critério que avalia o tempo médio que o paciente indígena aguarda para atendimento na unidade de saúde, em especial nos hospitais universitários, foi classificado como insatisfatório, sendo que a espera em média é superior a uma hora.

Outros dois pontos foram identificados como barreiras para o atendimento da população indígena em Cuiabá: a ausência de documentos pessoais de pacientes regulados, o que gera dificuldades na rede assistencial devido os sistemas de informação exigirem documentação; e o encaminhamento de indígenas do DSEI Cuiabá (Bororos - região Perigara) para atendimento de atenção básica em Cuiabá, sendo que o mesmo deveria ser feito em aldeia ou no município mais próximo da comunidade. Foi identificado que a assistência não tem ocorrido nas proximidades devido à falta de garantia de acomodações dos indígenas fora das aldeias nos municípios de referência, portanto, para a comodidade desta população torna-se mais fácil para o distrito sanitário o encaminhamento dos pacientes para a CASAI Cuiabá.

\section{Dimensão sociocultural}

A análise específica desta dimensão mostrou que os critérios avaliados foram classificados como parcialmente satisfatórios $(37,5 \%)$.

A primeira temática discutida foi a realização de rituais religiosos nos serviços especializados de saúde. Essa subdimensão, e seu respectivo critério, foi considerada satisfatória pelos entrevistados. Constatou-se que é assegurada a realização de rituais nos serviços especializados mediante a solicitação prévia do DSEI Cuiabá, no entanto, tais práticas estão estritamente relacionadas aos problemas de saúde do paciente. Como há rituais que envolvem fumaça, esses não são permitidos, em especial, para pacientes com doenças respiratórias.

O critério que aborda a adequação arquitetônica dos serviços especializados de saúde para o uso de redes foi considerado como insatisfatório pelos dados levantados junto aos entrevistados. Destaca-se, nesse critério, que os entrevistados alegaram não ter ocorrido, ao longo desses últimos anos, nenhuma demanda por parte dos usuários indígenas à CASAI Cuiabá e ao DSEI Cuiabá para cumprimento desse critério.

O critério que trata da capacitação dos profissionais de saúde da rede de serviços especializados de saúde de Cuiabá para atendimento aos usuários indígenas foi classificado como insatisfatório. Foi evidenciado que há preconceito em relação aos indígenas, que é explicitado de forma sutil ou de forma velada tanto por alguns profissionais de saúde quanto pela população em geral, que aguarda o atendimento nas unidades especializadas de saúde:

"Às vezes entro numa fila com uma indígena e há aqueles que olham achando bonita, porque tem índios muito bonitos, pintados, e o ser humano é curioso. ...mas tem muita gente que olha diferente, sai do banco onde sentamos e isso é feito pela população de uma forma geral. Para quem gosta e trabalha junto com os indígenas sofre muito, é a mesma coisa de estar dando um tapa na cara da gente... aí dentro do possível a gente tenta proteger" (Profissional 07).

$\mathrm{Na}$ temática alimentação, o item foi considerado parcialmente satisfatório. A análise evidenciou que, se algum paciente indígena tiver algum hábito alimentar diferenciado e estiver internado, ocasionalmente a instituição hospitalar recorre à CASAI para que esta forneça o alimento aos indígenas internados:

"Mas muitas vezes alguns hospitais falam: a gente não tem peixe essa semana. A gente já teve esses problemas e eles perguntam: a CASAI não pode comprar o peixe? Só que a gente não pode esquecer que a responsabilidade da Secretaria Especial de Saúde Indígena, da SESAI, e do Distrito é a atenção básica nas aldeias; a partir do momento em que ele sai pra rede à responsabilidade é do município e do Estado..." (Gestor 02). 


\section{Dimensão geográfica}

Esta dimensão tem uma subdimensão com dois critérios que tratam sobre a garantia de transporte dos pacientes indígenas da aldeia até os serviços de saúde especializados de Cuiabá e o tempo de deslocamento interno na cidade até os serviços de saúde. O tema transporte, juntamente com a discussão sobre as instalações físicas da CASAI Cuiabá, foi identificado como o principal elemento de insatisfação dos profissionais entrevistados, além de constar farta descrição sobre o assunto nos documentos analisados. Essa dimensão foi classificada como insatisfatória (25\%).

O DSEI Cuiabá é responsável pelo transporte dos pacientes até a CASAI Cuiabá, seja por meio de veículos próprios (carros ou barcos) que ficam nas aldeias/polos base, ou pelo fornecimento de passagens terrestres a partir de municípios de referência para as aldeias. Somente um município da área de abrangência do DSEI Cuiabá oferece transporte aos pacientes indígenas que precisam deslocar-se até Cuiabá. Alguns critérios foram instituídos pelos gestores do DSEI Cuiabá para transportar pacientes em veículos institucionais: pacientes idosos ou com dificuldade de locomoção possuem prioridade e, nos demais casos, são fornecidas passagens de ônibus. Nesses casos, cabe às aldeias/polo base providenciar o transporte de carro institucional da saúde para levar o paciente até o município onde embarcará em transporte intermunicipal até Cuiabá. A esse respeito, a maior parte das reclamações dos profissionais e gestores entrevistados fez referência à demora para expedição da passagem, havendo muitos casos em que pacientes perderam procedimentos agendados em Cuiabá em função de tal fato.

O deslocamento dos pacientes dentro do Município de Cuiabá não é realizado, na maioria das vezes, em menos de uma hora devido a alguns fatores como: a distância da CASAI da área central do município e as obras de mobilidade urbana que estão sendo realizadas na cidade, interditando várias avenidas e ruas. Essa situação, agravada por haver um único carro para o transporte, tem gerado atritos entre a equipe, gestores e pacientes:

"Já perdemos consulta por conta da ausência do carro. Carão nós levamos todo dia dos profissionais, porque a consulta era 13:00 e às vezes chegamos lá só às 15:00, aí a gente mente - mas eu acho que nós vamos para o céu assim mesmo" (Profissional 07).

Os documentos analisados também demonstram, em todo o período pesquisado, relatos, denúncias e reclamações de profissionais, conselheiros indígenas e mesmo gestores sobre o transporte. Os temas discutidos referem-se às más condições dos veículos oficiais, à falta de combustível e até dificuldades para liberação de passagens terrestres, ocasionando, conforme alguns depoimentos, a perda do agendamento de consultas e exames.

\section{Discussão}

Na dimensão sócio-organizacional evidencia-se uma fraca articulação entre o DSEI Cuiabá e os demais distritos sanitários com população indígena em Mato Grosso, com os municípios e estado. Tal fato também foi observado num estudo de avaliação das atividades desenvolvidas por entidades conveniadas com o órgão executor da saúde indígena (na época Fundação Nacional de Saúde - funasa) de sete DSEIs do Estado do Amazonas, onde foi identificado um fraco nível de articulação e integração dos distritos sanitários com os diferentes níveis de referência do SUS 20.

A PNASPI prevê uma atuação coordenada entre os diversos órgãos, no sentido de viabilizar a atenção integral à saúde dos povos indígenas. Para que isso ocorra, considera-se necessário o envolvimento harmônico dos gestores nacional, estaduais e municipais do SUS, por meio de planejamento pactuado nos DSEIs, resguardando o princípio final da responsabilidade federal. De acordo com essa política, cabe ao órgão federal executor da PNASPI promover e facilitar as articulações em níveis inter e intrassetoriais 6 .

Outro ponto a ser destacado refere-se à CASAI Cuiabá que conta com poucos recursos materiais/ logísticos e cujas instalações físicas estão precárias, dificultando o acolhimento integral do indígena, que deve ser uma das maiores preocupações de uma CASAI, uma vez que a mudança da aldeia para a cidade deve denotar respeito, conforto e garantir as especificidades culturais dos usuários indí- 
genas 21. Também no processo de cuidar da CASAI é necessário o cultivo de relacionamentos baseados na confiança, pois a produção de vínculo e afeto é considerada tecnologia leve que aproxima o trabalhador do universo do usuário 22 . Embora o uso de ferramentas relacionais seja importante no processo de cuidado ao indígena, e os profissionais relataram terem sido capacitados para atuação intercultural, alguns estudos apontam que os profissionais de saúde não indígenas de uma forma geral não são preparados para a atenção a esses povos, sendo que a baixa capacitação é reflexo das dificuldades de investimento social e politico e da conformação das políticas de saúde no Brasil 22,23,24. Além disso, um estudo realizado na Bolívia destaca que ao ser analisada a qualidade da atenção à saúde oferecida nos centros de saúde interculturais do país, foi alertado que, em muitos casos, o conceito de interculturalidade, discutido em cursos e fóruns apropriados para tal fim, é utilizado para encobrir as desigualdades das populações indígenas e, por vezes, pode ser uma forma de dominação social do Estado por meio de um discurso apaziguador, como estratégia para neutralizar o conflito étnico entre sujeitos e grupos diferentes 25 .

Na subdimensão organização dos serviços de saúde, constata-se que o tempo médio de espera dos indígenas para atendimento nos serviços de média e alta complexidades de Cuiabá apresenta resultados similares aos da pesquisa realizada junto ao povo Xakriabá, em Minas Gerais, uma vez que estes também aguardam em média de 1 a 4 meses para atendimento médico na média e alta complexidades do SUS 11. Embora os achados indiquem que o tempo acima de três meses para a consulta especializada esteja limitado a algumas especialidades, ainda assim percebe-se a necessária discussão da regionalização dos serviços de saúde e a fixação de profissionais especializados nas regiões de saúde de Mato Grosso.

Outro ponto evidenciado é o fato do sistema informatizado de regulação dos pacientes de Cuiabá permitir controlar o número de atendimentos realizados por cada profissional na forma de agendamentos previamente estabelecidos. Ainda assim, os pacientes indígenas são atendidos por ordem de chegada na unidade de saúde, sem qualquer cumprimento do horário agendado. Isso tem causado situações estressantes, em especial para os pacientes que viajam por muitas horas buscando o atendimento em Cuiabá. Embora ao se analisar o foco dos sistemas de regulação, que são estruturas operacionais que racionalizam a entrada e a continuidade do tratamento no sistema de saúde, de acordo com graus de risco e normas definidas em protocolos, visando à regulação de fluxos e processos de forma a garantir um acesso regulado, mais equitativo 26 , verifica-se que na realidade tal objetivo não tem sido cumprido em sua integralidade em Cuiabá. A ação regulatória deve monitorar e avaliar, dentre outros fatores, os procedimentos realizados pelos profissionais de saúde, visando ao efetivo cumprimento dos protocolos estabelecidos 27.

$\mathrm{Na}$ dimensão sociocultural, sobressai nos achados levantados a incipiência de conhecimentos de aspectos socioculturais que interferem no processo saúde/doença dos povos indígenas, por parte dos serviços de saúde especializados de Cuiabá. Diferentes estudos realizados com populações indígenas em todo o mundo enfatizam a necessidade de constituir-se serviços de saúde culturalmente sensíveis, em diferentes níveis de atenção à saúde, visando a resgatar a cultura ao centro da relação entre pacientes e serviços de saúde. O conceito de segurança cultural vai além da aprendizagem de informações factuais sobre dieta e necessidades religiosas dos diferentes grupos étnicos. Ou seja, significa um envolvimento com o contexto sociopolítico de crenças e o reconhecimento de uma variedade de práticas de saúde, e que para uma abordagem integral e humana a cultura é um elemento essencial 28,29,30.

Trabalhos realizados com populações indígenas do Chile e com Povos do Pacífico confirmam que diferentes povos indígenas, em todo o mundo, citam dificuldades no relacionamento entre pacientes e médicos, além da percepção de indiferença e do tratamento discriminatório na relação com os profissionais dos serviços de saúde. Verificou-se que tais aspectos constituem barreiras, pois os pacientes relutam em procurar os serviços de saúde biomédicos 31,32.

As discussões sobre estabelecimentos de saúde hospitalar culturalmente sensíveis aos povos indígenas, com capacidade de atuação dentro de contexto intercultural, foram reconhecidas pelo Estado Brasileiro a partir da promulgação da Portaria no 645 de 27 de março de 2006, que instituiu o certificado hospital amigo do índio a ser oferecido aos estabelecimentos de saúde da rede SUS. No entanto, essa Portaria nunca foi regulamentada e, segundo informações da Secretaria Especial de Saúde Indígena (SESAI), não há nenhum hospital brasileiro com tal certificação. A ausência dessa discussão no 
cenário nacional, que já perdura dez anos, evidencia a fragilidade política do setor para a constituição do resgate da humanização do cuidado e da integralidade da atenção à saúde dos povos indígenas.

Apesar de todos os problemas identificados na dimensão sociocultural, o fato dessas barreiras não terem sido consideradas pelos entrevistados como empecilho para o atendimento de saúde aos indígenas em Cuiabá, reforça um achado constatado num estudo realizado no Canadá onde ao pesquisar sobre a percepção dos profissionais de saúde acerca das barreiras de tratamento do diabetes entre povos indígenas, evidenciou-se que os profissionais não citaram barreiras socioculturais como relevantes no processo de tratamento de saúde dos indígenas canadenses. Os autores asseveram que os profissionais desconheciam o quanto pode ser significativo o aspecto cultural na discussão da saúde indígena. Segundo eles, faz-se então necessário implantar uma educação e treinamento sobre o tema da interculturalidade e serviços culturalmente seguros para os profissionais de saúde 33 .

Na dimensão geográfica fica evidenciado que a questão do transporte em saúde de pessoas é considerada uma das principais barreiras ao acesso dos usuários, em geral, aos serviços de saúde 26 . Um estudo realizado com população indígena do México também apontou o acesso geográfico como uma grande barreira aos pacientes indígenas que buscam atendimento nos serviços de saúde 3 . Esse fato decorre da localização das residências dos pacientes que, normalmente, são em áreas rurais, de difícil acesso e distantes dos centros de saúde, em especial os especializados. Na Austrália, há relato da criação de um serviço móvel de atendimento especializado que se desloca até áreas distantes onde estão as populações aborígenes, com o intuito de apoiar ações da atenção básica e minimizar as barreiras de acesso geográfico aos serviços de saúde 34 .

\section{Considerações finais}

A aplicação da matriz de avaliação de acessibilidade dos usuários indígenas trouxe evidências de que todas as dimensões estudadas apresentaram barreiras que dificultam a acessibilidade da população indígena de Mato Grosso aos serviços de saúde de Cuiabá.

Como principais limitações metodológicas do presente trabalho, destacam-se a ausência de informações sobre as barreiras enfrentadas por usuários indígenas que não acessaram a CASAI; as gradações/parâmetros utilizados que podem ter limitado a compreensão das evidências; e a ausência de escuta dos profissionais e gestores dos serviços especializados de saúde de Cuiabá, assim como de usuários indígenas. Estimula-se o desenvolvimento de pesquisas sobre o acesso à saúde indígena, ampliando a análise para todos os atores envolvidos no processo de integração dos serviços de saúde.

Recomenda-se aperfeiçoamento da PNASPI, visando: a constituir serviços de saúde culturalmente sensíveis nos diferentes níveis de atenção do SUS; a efetivar normatização de protocolos que garantam a articulação do subsistema de saúde indígena com a rede de atenção básica, média e alta complexidades dos municípios e estados; a efetivar a participação igualitária entre os gestores das diferentes esferas do governo nos colegiados de pactuação locais; e à constituição de colegiados específicos entre gestores da saúde indígena de um mesmo estado, para a garantia de pactuações e normatizações entre os diferentes distritos sanitários. 


\section{Colaboradores}

S. C. Gomes participou da concepção e desenho do projeto, coleta, análise e interpretação dos dados e redação do artigo. M. A. Esperidião colaborou na concepção e desenho do projeto, análise e interpretação dos dados, redação do artigo, revisão crítica do conteúdo intelectual e aprovação final da versão a ser publicada.

\section{Referências}

1. Gao S, Manns BJ, Culleton BF, Tonelli M, Quan $\mathrm{H}$, Crowshoe L, et al. Access to health care among status Aboriginal people with chronic kidney disease. CMAJ 2008; 179:1007-12.

2. Zuckerman S, Haley J, Roubideaux Y, LillieBlanton M. Health service access, use, and insurance coverage among American Indians/ Alaska Natives and whites: what role does the Indian health service play? Am J Public Health 2004; 94:53-9.

3. Mendoza EM. Percepción de los habitantes indígenas de áreas rurales respecto al primer nível de atención médica. El caso del sureste de Veracruz, México. Salud Colect 2011; 7:73-86.

4. Hautecoeur M, Zunzunegui MV, Vissandjee B. Las barreras de acceso a los servicios de salud em la población indígena de Rabinal en Guatemala. Salud Pública Méx 2007; 49:86-93.

5. Chaves MBG, Cardoso AM, Almeida C. Implementação da política de saúde indígena no Pólo-base Angra dos Reis, Rio de Janeiro, Brasil: entraves e perspectivas. Cad Saúde Pública 2006; 22:295-305.

\section{Agradecimentos}

Aos profissionais e gestores do DSEI Cuiabá e da CASAI Cuiabá, à Secretaria de Estado de Saúde de Mato Grosso e Instituto de Saúde Coletiva, Universidade Federal da Bahia (ISC/UFBA).
6. Ministério da Saúde. Portaria no 254, de 31 de janeiro de 2002. Aprova a Política Nacional de Atenção à Saúde dos Povos Indígenas. Diário Oficial da União 2002; 6 fev.

7. Souza Filho ZA, Ferreira AA, Santos B, Pierin AMG. Prevalência de hipertensão arterial em indígenas do Brasil: uma revisão sistemática com meta-análise. Rev Esc Enferm USP 2015; 49:1016-26.

8. Imbiriba EB, Basta PC, Pereira ES, Levino A, Garnelo L. Hanseníase em populações indígenas do Amazonas, Brasil: um estudo epidemiológico nos municípios de Autazes, Eirunepé e São Gabriel da Cachoeira (2000 a 2005). Cad Saúde Pública 2009; 25:972-84.

9. Arantes R, Santos RV, Coimbra Jr. CEA. Saúde bucal na população indígena Xavante de Pimentel Barbosa, Mato Grosso, Brasil. Cad Saúde Pública 2001; 17:375-84.

10. Levino A, Oliveira RM. Tuberculose na população indígena de São Gabriel da Cachoeira, Amazonas, Brasil. Cad Saúde Pública 2007; 23:1728-32. 
11. Errico LSP. Acesso e utilização dos serviços de saúde da população da etnia Xakriabá, norte de Minas Gerais [Tese de Doutorado]. Belo Horizonte: Universidade Federal de Minas Gerais; 2011.

12. Vargas KD, Misoczky MC, Weiss MCV, Costa WGA. A (des)articulação entre os níveis de atenção à saúde dos Bororo no Polo-base Rondonópolis do Distrito Sanitário Especial Indígena de Cuiabá, MT. Physis (Rio J.) 2010; 20:1399-418.

13. Cintra EVCS, Weiss MCV, Misoczky MC, Bordin R. Fluxo dos Paresi entre os níveis de atenção à saúde no Distrito Sanitário Especial Indígena de Cuiabá, Mato Grosso. Saúde Debate $2012 ; 36: 133-42$.

14. Prefeitura de Cuiabá. Plano municipal de saúde 2010-2013. Cuiabá: Prefeitura de Cuiabá; 2010.

15. Cunha ABO, Vieira-da-Silva LM. Acessibilidade aos serviços de saúde em um município do Estado da Bahia, Brasil, em gestão plena do sistema. Cad Saúde Pública 2010; 26:725-37.

16. Teixeira CF. Planejamento municipal em saúde. Salvador: Instituto de Saúde Coletiva, Universidade Federal da Bahia; 2001.

17. Donabedian A. Los espacios de la salud: aspectos fundamentales de la organización de la atención médica. México DF: Editorial Biblioteca de la Salud; 1988.

18. Dever GEA. Epidemiologia na administração dos serviços de saúde. São Paulo: Pioneira; 1988.

19. Minayo MCS, Assis SG, Souza ER, organizadoras. Avaliação por triangulação de métodos: abordagem de programas sociais. Rio de Janeiro: Editora Fiocruz; 2005.

20. Garnelo L, Brandão LC. Avaliação preliminar do processo de distritalização sanitária indígena no Estado do Amazonas. In: Coimbra Jr. CEA, Santos RV, Escobar AL, organizadores. Epidemiologia e saúde dos povos indígenas no Brasil. Rio de Janeiro: Editora Fiocruz/Abrasco; 2005. p. 235-57.

21. Guzzardi A. O Projeto Casai/Cirsai. In: Nery TCS, Guzzardi A, organizadores. Saúde indígena: 1o curso de atenção terciária. São Paulo: Editora Limiar/Brasília: Fundação Nacional de Saúde; 2005. p. 33-5.

22. Ribeiro AA, Fortuna CM, Arantes CIS. O trabalho de enfermagem em uma instituição de apoio ao indígena. Texto Contexto Enferm $2015 ; 24: 138-45$.
23. Novo MP. Política e intermedicalidade no Alto Xingu: do modelo à prática de atenção à saúde indígena. Cad Saúde Pública 2011; 27:136270.

24. Gonçalves LJM. Entre culturas: uma experiência de intermediação em saúde indígena. São Paulo: Universidade de São Paulo; 2007.

25. Hita SR. Calidad de atención en salud: prácticas y representaciones sociales em las poblaciones quechua y aymara del altiplano boliviano. 2a Ed. La Paz: Organización Panamericana de la Salud; 2010.

26. Mendes EV. As redes de atenção à saúde. Brasília: Organização Pan-Americana da Saúde; 2011.

27. Vilarins GCM. Regulação do acesso à assistência: conceitos e desafios. Comun Ciênc Saúde 2010; 21:81-4.

28. McPherson KM, Harwood M, McNaughton HK. Ethnicity, equity and quality: lessons from New Zealand (Nga mātawaka, nga āhua tika me nga painga: nga ākoranga no Aotearoa). Qual Saf Health Care 2003; 12:237-38.

29. Oliveira FA. Antropologia nos serviços de saúde: integralidade, cultura e comunicação. Interface Comun Saúde Educ 2002; 6:63-74.

30. Hamilton J. Multicultural health care requires adjustments by doctors and patients. CMAJ 1996; 155:585-7.

31. Alarcón AM, Astudillo P, Barrios S, Rivas E. Política de salud intercultural: perspectiva de usuários mapuches y equipos de salud em la IX región, Chile. Rev Méd Chile 2004; 132:1109114.

32. Kaholocuaa JK, Saito E, Mau MK, Latimer $\mathrm{R}$, Seto TB. Pacific islanders' perspectives on heart failure management. Patient Educ Couns 2008; 70:281-91.

33. Bhattacharyya OK, Estey EA, Rasooly IR, Harris S, Zwarenstein M, Barnsley J. Providers' perceptions of barriers to the management of type 2 diabetes in remote Aboriginal settings. Int J Circumpolar Health 2011; 70:552-63.

34. Gruen RL,Weeramanthri TS, Bailie RS. Outreach and improved access to specialist services for indigenous people in remote Australia: the requirements for sustainability. J Epidemiol Community Health 2002; 56:517-21. 


\section{Abstract}

This study aimed to evaluate indigenous peoples' access to medium and high-complexity health services in the municipality of Cuiabá, Mato Grosso State, Brazil, through the Casa de Saúde Indigena or Indigenous Peoples' Clinic (CASAI Cuiabá). A single case study with a qualitative approach was conducted at CASAI Cuiabá. Data were obtained from observation of the work routines at CASAI Cuiabá, semi-structured interviews with health professionals and administrators from the Cuiabá Special Indigenous Health District (DSEI) and CASAI Cuiabá, and document analysis. Data analysis used a matrix derived from the theoretical and logical model of accessibility, validated by the Delphi method with a group of experts on indigenous peoples' health. Despite advances achieved by CASAI in improving indigenous peoples' access, there are persistent social, organizational, cultural, and geographic barriers in access to medium and high-complexity health services in Cuiabá. The study highlights the need for specific strategies to improve access to health services by indigenous peoples in Mato Grosso State.

Health of Indigenous Peoples; Health Services Accessibility; Health Evaluation

\section{Resumen}

Este trabajo tuvo como objetivo evaluar el acceso de los usuarios indígenas a los servicios de salud de mediana y alta complejidad del municipio de Cuiabá, Mato Grosso, Brasil, a partir de la CASAI Cuiabá. Se realizó un estudio de caso único en la Casa de Salud Indígena (CASAI) Cuiabá con un enfoque cualitativo. Los datos se obtuvieron mediante observación de las rutinas de trabajo de la CASAI Cuiabá, entrevistas semiestructuradas con profesionales y gestores del Distrito Sanitário Especial Indígena (DSEI) Cuiabá y CASAI Cuiabá, y un análisis documental. Para el análisis de datos, se elaboró una matriz derivada del modelo teórico-lógico de accesibilidad, y validada mediante el método Delphi, a un grupo de especialistas en la temática de salud indígena. A pesar de los avances que conlleva la CASAI en la mejoría de la accesibilidad indígena, persisten barreras socioorganizativas, culturales y geográficas en el acceso a los servicios de mediana y alta complejidad del municipio estudiado. Se recomienda la formulación de estrategias específicas para la mejora del acceso a los servicios de salud de los pueblos indígenas matogrosenses.

Salud de Poblaciones Indígenas; Accesibilidad a los Servicios de Salud; Evaluación en Salud
Recebido em 17/Ago/2015

Versão final reapresentada em 13/Jun/2016 Aprovado em 24/Jun/2016 